\title{
Algorithm of Differential-protection on Rectifier Valve Group of the Electrolytic Aluminum Rectification System
}

\author{
Xiaodong Zhao ${ }^{1}$, Ya Zhang ${ }^{2}$, Bei Tian ${ }^{1}$, Xutao $\mathrm{Li}^{1}$, Di Zhang ${ }^{1}$ and Zhiguo Hao ${ }^{2}$ \\ ${ }^{1}$ State Grid Ningxia Electric Power Company Electric Power Research Institute in Yinchuan City of Ningxia Province, China \\ ${ }^{2}$ Xi' an Jiao Tong University in Xi'an City of Shaanxi Province, China
}

\begin{abstract}
The rectifier group is an important equipment for the electrolytic aluminum rectification system. The valve short circuit and valve breakdown failure, which would cause serious accidents, often happened. The sensitivity of the existing arc protection action is affected by the fault position, and the equipment burning accident, caused by the failure to detect in time, happened frequently. This paper derived the AC/DC differential protection algorithm of the rectifier group which was based on the structure of the rectifier group and conceived from the idea of "valve short circuit protection". The simulation results showed that the algorithm can identify the fault, which occurred inside, quickly and accurately. This algorithm provides a new method for the protection of the rectifier valve group, which fills the gap of the differential protection of the rectifier valve group.
\end{abstract}

Keywords- rectifier valve group; valve short circuit protection; AC/DC differential protectio

\section{INTRODUCTION}

The rectifying valve group is an important equipment of electrolytic aluminum rectifier system, its safety and reliability will directly affect the normal production of electrolytic aluminum, if there is a serious fault, not only directly affect the normal production of electrolytic series, and the direct and indirect economic losses is incalculable [1,2]. In recent years, with the continuous expansion of the scale of the electrolytic aluminum's production, rectifying device capacity is also growing and the number of parallel operation of rectifier unit increases. when the short-circuit fault occurs, if the fault is not removed timely, the local short-circuit point of one unit soon become a common short point of several other units, which would lead rectifier explosion. In the past, the protection device of the electrolytic rectifier system is set on the AC side, and the protection action time is usually 300 500ms. In this case, the damage of the rectifier valve set is very serious, and it cannot protect the equipment safety.

In order to enhance the protection of the rectifying valve group and to ensure the continuity and reliability of power supply, the principle of countercurrent protection of the aluminum electrolytic DC rectifier system is analyzed in [3]. It shows that the current protection can be used as DC backup protection, and it can act when the short circuit occurs in the power supply rectifier internal bus and output rectifier DC bus. The installation principle and system configuration of countercurrent protection device for rectifier valve group are given in document $[4,5]$, and in it, the importance of counter current protection in electrolysis industry is expounded. In engineering application, counter current protection has been improved continuously[6,7], but its principle determines that it can only remove the fault when short circuit fault occurs on the bus[3]. The existing protection cannot quickly remove the arc fault and the protection cannot cover the entire manifold. In order to solve this problem, the [8-10] introduces the protection principle of arc protection, and proves that the arc protection can solve the harm caused by the electric arc and minimize the damage[11], which would provide security for the electrolytic aluminum industry. But in the initial of the slight valve fault or valve short, arc protection cannot reliably start. Therefore, the study of AC / DC differential protection algorithm for rectifier valve set is of great significance to the safe and stable operation of the equipment.

The paper begins with the structure of the rectifier group, followed by the derivation of the algorithm of the AC and DC differential protection algorithm of the rectifier valve group. And finally, the reliability of the algorithm is verified by simulation.

\section{STRUCTURE OF RECTIFYING VALVE SET}

The rectifier valve group, which constitute a rectifier unit with multi-tap regulator transformer, phase-shifting transformer together, is one of the important equipment for electrolytic aluminum production. It achieves the transition from alternating current to direct current required for electrolytic aluminum production. The high-voltage AC into the line is regulated by the voltage regulating transformer and is changed the phase by the phase shifted transformer. Then the rectifier valve cabinet supplies the direct current load of the production system with adjustable voltage and high current.

A ZHSPTB-117000/330 type rectifier transformer used in an electrolytic aluminum plant is used as a reference, as shown in figure 1. It can be seen from the figure, the rectifier transformer is divided into three parts from the structure: autoloaded voltage regulator transformer, two four-winding twisted-pair wiring phase-shifting transformer and rectifier circuit. In practice, the three part does not package together. The voltage-controlled transformer is separately assembled in a fuel tank and connected by two parallel phase-shifting transformers through the GIS bus. Then 12 pulses caused by the phase-shifting transformer into the rectifier cabinet. Finally, 
the rectifier cabinet converts the alternating current into a DC bus through a reverse parallel diode.

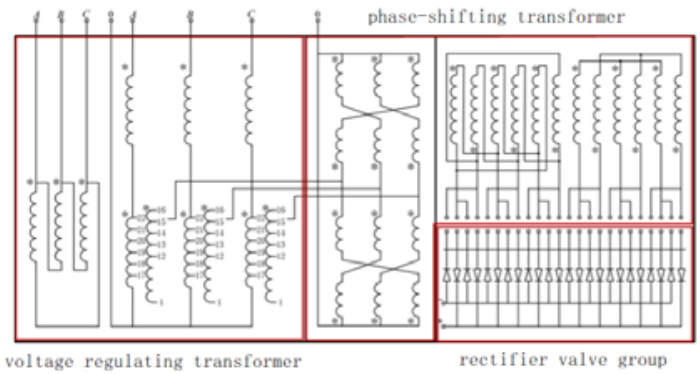

FIGURE I. WIRING DIAGRAM OF RECTIFIER TRANSFORMER OF AN ELECTROLYTIC ALUMINUM FACTORY

It can be seen from the rectifier valve group of Fig.1 that rectifier group is constructed by four three-phase bridge rectifier circuits in parallel. Rectifier circuit is completely enclosed in the box, and the inlet side is 12 pulsating AC power supply, while the outlet side is a DC power supply and the two ports are respectively connected with the positive and negative buses. Theoretically, the rectifier valve group differential protection can take the three-phase bridge rectifier circuit as the protection interval. But considering the encapsulation of rectifier valve cabinet, it is impossible to measure the current at the DC outlet of a single bridge circuit. Only the current at the two port of the valve group can be measured. Therefore, the entire rectifier valve group is a protective interval in differential protection.

In the rectifier unit, the breaker only exists in high side of voltage regulating transformer. There is no circuit breaker between the voltage-regulating transformer, the phase-shifting transformer and the rectifier valve group. Therefore, no matter where the rectifier unit fails, only the breaker on the high voltage side of the voltage regulating transformer is required to be disconnected to detect the fault.

\section{AC AND DC DIFFERENTIAL PROTECTION OF RECTIFIER VALVE GROUP}

\section{A. Protection Principle And Algorithm Deduction}

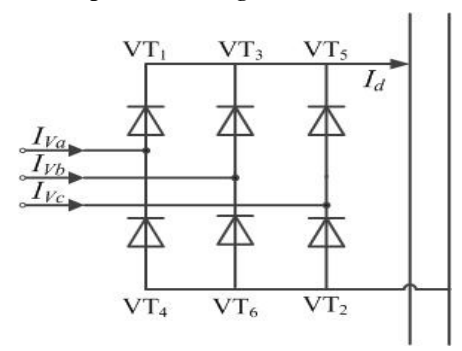

FIGURE II. THREE-PHASE BRIDGE RECTIFIER CIRCUIT SCHEMATIC

As the rectifying valve group, rectifier and inverter in HVDC transmission system based on three-phase bridge rectifier circuit, so the valve short circuit protection [12] is also applicable to the single bridge circuit rectifier valve group, but due to the rectifying valve group must be based on a complete whole flow valve to protect the cabinet interval, so this protection must be improved. The three-phase bridge rectifier circuit in Figure 2 is used to illustrate the "short circuit protection of the valve".

In normal operation, the AC side three-phase current turns in turn. Every moment there is only one common cathode diode (VT1, VT3, VT5) and a common anode diode (VT4, VT6, VT2) conduction. The conducting diode will use its voltage to turn off the other diodes in parallel with its poles, that is, the AC side has only one phase which is forward conduction and one reverse conduction. They form the loop with DC side bus and load. In the case of ignoring other current losses, it can be considered that the maximum amplitude current (conduction phase current) flowing through the diode and the DC current are the same current loop. So, the absolute maximum value of the three-phase alternating current(instantaneous) is equal to the DC current, given in (1), where $i_{v a}(t), i_{v b}(t), i_{v c}(t)$ is instantaneous value of $\mathrm{AC}$ side current for rectifier valve cabinet and $i_{d}(t)$ is DC side current instantaneous value.

$$
\left|\max \left(i_{v a}(t), i_{v b}(t), i_{v c}(t)\right)\right|=i_{d}(t)
$$

When the fault occurs, the formula(1) is no longer established, and the fault can be identified by the use of type(2), where $I_{\text {set }}$ is the setting value of protection.

$$
\left|\max \left(i_{v a}(t), i_{v b}(t), i_{v c}(t)\right)\right|-i_{d}(t)>I_{\text {set }}
$$

Valve short-circuit protection can accurately identify the various types of faults of the rectifier valve group, such as straight diode short circuit, AC line single-phase short-circuit, phase short circuit, DC bus short circuit. It can be completely applicable to three-phase bridge rectifier circuit. However, a rectifier valve is composed of four bridge rectifier circuit in parallel. There are multiple diodes at the same time positive conduction, so the above formula (2) has not been established.

Although the valve short circuit protection cannot be applied directly to the rectifier valve group, the basic principle of the rectifier circuit is similar. Therefore, the fundamental idea of studying the AC/DC differential protection of the rectifier group can refer to the short circuit protection of the valve: establishing the equation of instantaneous current between AC side and DC side by analyzing the working principle of the rectifier circuit. Because the valve fault will cause the fault current flowing through the great valve, the failure to remove the fault in time will lead to a large number of converter diodes burned, causing significant economic losses and lead to maintenance time up to several months, which is a very serious fault. In order to avoid the large amount of converter diode damage caused by faults, the operation time of the converter is very strict. It is generally required to operate the exit at $5 \mathrm{~ms}$. Therefore, valve short circuit protection is generally without delay.

Rectifier valve group internal principle is shown in Figure 3, where all arrow directions are the reference flow for the instantaneous current. $i_{1(a, b, c)}, i_{2(a, b, c)}, i_{3(a, b, c)} 、 i_{4(a, b, c)}$, the 
four parallel three-phase bridge circuits are connected to the 12-pulsating alternating current of the rectifier group. ${ }^{i}$ is the DC side current. Based on the relationship between the instantaneous current on the AC side and that of the DC side, it can be observed that the forward conduction diode on the AC side provides current for the DC side. Therefore, as long as the positive instantaneous current of the AC side is obtained, can the differential equations of the AC/DC differential protection be deduced.

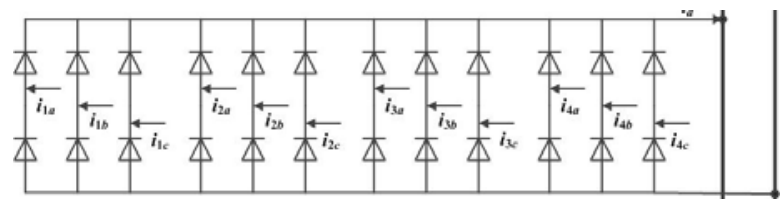

FIGURE III. RECTIFIER VALVE GROUP RECTIFIER CIRCUIT DIAGRAM

The current in the positive reference direction is part of the direct current. The instantaneous current of forward reference flow can be extracted by comparing with 0 . The greater than 0 is the positive direction, and the less than 0 is the negative direction. The forward current is added to get the formula (3), where the electric current is instantaneous.

$$
i_{\text {sum }(A C \rightarrow D C)}(t)=\sum_{n=1}^{4} \max \left[i_{(n) a}(t), 0\right]+\sum_{n=1}^{4} \max \left[i_{(n) b}(t), 0\right]+\sum_{n=1}^{4} \max \left[i_{(n) c}(t), 0\right]
$$

Formula 4 is obtained by Kirchhoff's law.

$$
i_{\text {sum }(A C \rightarrow D C)}(t)=i_{d}(t)
$$

As shown in equation (5), when a fault occurs, $i_{\text {sum }(A C \rightarrow D C)}(t)$ includes not only the DC side current, but also the fault current.

$$
i_{\text {sum }(A C \rightarrow D C)}(t)=i_{d}(t)+i_{f}
$$

Because in normal conditions, the DC side current is pulsating, rather than flat. Moreover, in the normal state, the fundamental component of the current is very small, but in the fault state, both the differential current and the braking current have larger fundamental frequency components. The phasor value is obtained by Fourier transformation, and the equation of AC and DC differential protection applicable to rectifier valve cabinet can be obtained. In equation (6), $I_{\text {set }}$ is the setting value, and the setting of the setting valve is based on the rated current of the DC side.

$$
\left|\dot{I}_{\text {sum }(A C-D C)}-\dot{I}_{d}\right|>I_{\text {set }}
$$

\section{B. Selection of Protection Value}

Due to the large load current, the AC/DC differential protection adopts ratio differential, and the required parameters are the starting current and the coefficient $\mathrm{k}$ of the protection.
Equation (6) is set as a protection criterion, and the setting value is as follows:

$$
I_{\text {set }}=\max \left(I_{0}, k I_{\text {res }}\right)
$$

In the formula(7), the value of $I_{r e s}$ is equal to the value of $I_{d}$

, which is the current of the DC side of rectifier valve group.

At present, some DC engineering valve short circuit protection is still using the traditional AC ratio differential protection rules. Setting and proportionality coefficients of different DC systems are different. The starting current needs to be adjusted according to the principle of avoiding the maximum imbalance current in the normal conditions, and $0.3 \sim 0.5$ is usually used. The setting of the scale factor needs to consider the maximum unbalanced current produced by the measurement circuit when the most critical fault and avoid it. The measuring error of AC transformer is calculated by $0.5 \%$. The measurement error of current transformer and zero flux current transformer is calculated by $0.3 \%$, and the coefficient of proportionality $\mathrm{k}$ is 0.2 .

According to the model parameters of the rectifier valve set used in this paper, the starting current is set to 0.4, and the coefficient of proportionality $\mathrm{k}$ is set to 0.2 . The specific protection characteristic curve is shown in figure 4 . The AC side current value is calculated by the equation (3), and the differential current value is the result which is obtained by subtracting the DC side current rms from the AC side current rms. The braking current is the effective value of the AC side current. The current data used for calculation is the per unit value, and their reference value is $1 \mathrm{kA}$.

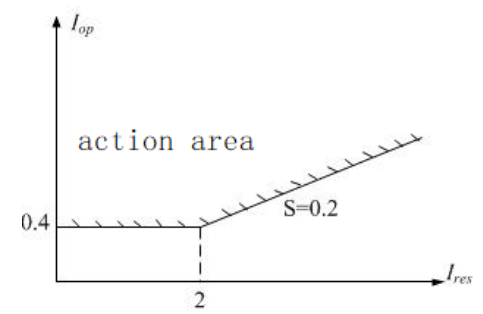

FIGURE IV. CHARACTERISTIC CURVE OF AC/DC DIFFERENTIAL PROTECTION

\section{ALGORITHM VALIDATION}

In order to verify the reliability of the AC/DC differential protection of the rectifier group, the simulation model of the rectifier transformer is set up with PSCAD. The schematic diagram of the simulation principle is shown in Fig1, and the simulation principle of the rectifier group is shown in Fig3.

Combined with actual production and analysis, there may be 5 kinds of short-circuit faults as follows: diode short circuit, single-phase short earth fault occurs on AC input line, interphase short circuit fault occurs on the AC input line, interphase short circuit fault occurs on the adjacent line of the AC incoming line, short circuit fault occurs on the DC bus. So in the algorithm validation, only these five kinds of failures are simulated and analyzed. Using Matlab to deal with simulation 
data, we get the fault protection action diagram shown in Fig5, 6 and 7.

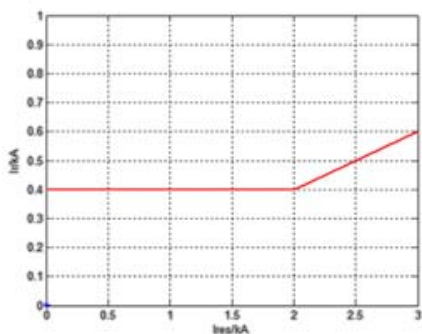

FIGURE V. TROUBLE-FREE PROTECTION ACTION DIAGRAM

As can be seen from Figure 5, protection does not operate under normal conditions. The protection action diagram is similar to that when the fault is outside, and the protection will not operate. The simulation results show that the algorithm can guarantee that the differential protection cannot malfunction when the fault is out of the zone.

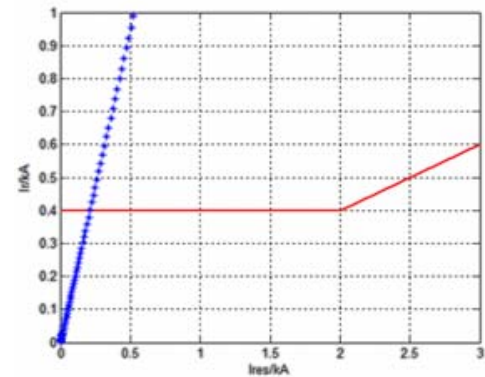

FIGURE VI. DIODE SHORT-CIRCUIT PROTECTION ACTION DIAGRAM

The other three typical fault protection actions are similar to those shown in Figure 6 and 7. As can be seen from the diagram, the protection can operate reliably when the fault is in the zone. The current data of the rectifier valve group and the operation of the protection under different running conditions are shown in Table 1 , Where the data is the value of $5 \mathrm{~ms}$ after the fault. And ' $\mathrm{Y}$ ' represents that detecting the faults, while ' $N$ ' represents that no fault is detected.

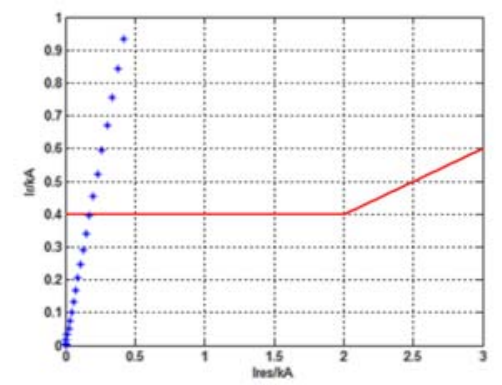

FIGURE VII. THE PROTECTION ACTION DIAGRAM OF INTERPHASE SHORT CIRCUIT FAULT OCCURING ON THE AC INPUT LINE
TABLE I. CALCULATION AND OPERATION OF DIFFERENTIAL PROTECTION UNDER VARIOUS OPERATING CONDITIONS

\begin{tabular}{|c|c|c|c|c|}
\hline \multicolumn{2}{|r|}{ running state } & $\begin{array}{l}\text { Differential } \\
\text { current }\end{array}$ & $\begin{array}{c}\text { Action } \\
\text { value }\end{array}$ & result \\
\hline \multicolumn{2}{|c|}{ Normal } & 0 & 0 & $\mathrm{~N}$ \\
\hline \multirow{5}{*}{$\begin{array}{l}\text { Intra- } \\
\text { regional } \\
\text { failure }\end{array}$} & diode short circuit & 70.75 & 10.63 & $\mathrm{Y}$ \\
\hline & $\begin{array}{l}\text { single-phase short } \\
\text { earth fault occurs on } \\
\text { AC input line }\end{array}$ & 27.61 & 3.73 & $\mathrm{Y}$ \\
\hline & $\begin{array}{l}\text { interphase short } \\
\text { circuit fault occurs } \\
\text { on the AC input line }\end{array}$ & 45.32 & 6.81 & $\mathrm{Y}$ \\
\hline & $\begin{array}{l}\text { interphase short } \\
\text { circuit fault occurs } \\
\text { on the adjacent line } \\
\text { of the AC incoming } \\
\text { line }\end{array}$ & 31.19 & 8.41 & $\mathrm{Y}$ \\
\hline & $\begin{array}{l}\text { short circuit fault } \\
\text { occurs on the DC } \\
\text { bus }\end{array}$ & 78.05 & 15.61 & $\mathrm{Y}$ \\
\hline \multirow{3}{*}{$\begin{array}{l}\text { Out } \\
\text { of zone } \\
\text { fault }\end{array}$} & $\begin{array}{c}\text { Single phase } \\
\text { grounding }\end{array}$ & 0 & 1.14 & $\mathrm{~N}$ \\
\hline & $\begin{array}{l}\text { Two-phase } \\
\text { grounding }\end{array}$ & 0 & 3.27 & $\mathrm{~N}$ \\
\hline & $\begin{array}{l}\text { Two-phase short- } \\
\text { circuit }\end{array}$ & 0 & 2.66 & $\mathrm{~N}$ \\
\hline
\end{tabular}

It can be seen from Table 1 that the algorithm can reliably identify the fault in the area. when the fault is in the area, the fault can be reliably identified within $5 \mathrm{~ms}$. And in the event of an external fault, protection is not malfunctioning. Based on the above simulation results, the proposed algorithm of rectifier group can quickly and reliably identify various faults of the valve group.

\section{SUMMARY}

Based on the structural characteristics and working principle of the rectifier group, the AC/DC differential protection algorithm is proposed by improving the "valve short circuit protection" used in DC transmission. The reliability of the algorithm is verified by simulation.

The algorithm proposed in this paper fills the blank of the differential protection of the rectifier valve group. Voltage transformer differential protection, phase-shifting transformer differential protection and it together constitute the differential protection of the entire rectifier unit to ensure the safe operation of the rectifier unit.

\section{REFERENCES}

[1] Zhang H, Zhang M. Summary on $220 \mathrm{kV}$ Large Electrolytic Aluminium Rectifier Transformers[J]. Transformer, 2000.

[2] Piccone D E, Rosser D B. SEMICONDUCTOR RECTIFIER ASSEMBLY HAVING HIGH EXPLOSION RATING: US, US 3581160 A[P]. 1971.

[3] Wei Y L. Adjustment Principle and Range of Rectifier Transformer's Constant Current Control System for Aluminum Electrolysis[J]. NonFerrous Metallurgical Equipment, 2007.

[4] Selvaraju P, Bagalay R A. Reverse current protection for power converters having synchronous rectifiers: US, US 20070165429 A1[P]. 2007.

[5] Ding G. No Need to Set Up Reverse Current Protection in Rectifiers[J]. Urban Rapin Rail Transit, 2005.

[6] Chen L S, Zheng X U, Hui $\mathrm{H}$, et al. A Case Analysis and Countermeasure on Cleaner Production of Aluminum Electrolysis Industry[J]. Journal of Kunming Metallurgy College, 2013. 
[7] Pei B, Zhao L. Application of Rectifier Circuits Controlled with Balance Reactor in Aluminum Electrolysis Casting Device[J]. Foundry Technology, 2013.

[8] Hong-Qin F U. Design and Application of Arc Protection in Electrolytic Aluminum Rectification System[J]. Automation Application, 2010.

[9] Shi L, Chen Y N. The Application of One Improved Electric Arc Protection Device in Electrolytic Aluminium Industry[J]. Development \& Innovation of Machinery \& Electrical Products, 2015.

[10] Takahashi N, Funasaka H, Shimizu T. Formation of Aluminium Oxide Film on Al Substrate by Micro-Arc-Technology in Electrolytic Solution of Sodium Phosphate Systems[J]. Journal of the Ceramic Society of Japan, 2005, 113(1318):429-434.

[11] Chen G Q. Improvement on Measuring Method for Current Equalizer Coefficient of Rectifier Cabinet[J]. Energy Saving of Nonferrous Metallurgy, 2010.

[12] Yao M, Yingwen L I, Meng Y, et al. Improvement of Valve Short Circuit Protection in Lingbao Converter Station Based on Kirhhoff's Current Law with Both Sides[J]. Shaanxi Electric Power, 2016 